\title{
Is Hysterosalpingography using Magnetic Resonance Imaging a promising tool in infertility patients?
}

\author{
Ankita Sethi ${ }^{1}$, Neeta Singh ${ }^{1}$, Garima Patel ${ }^{1}$ \\ ${ }^{1}$ Division of Reproductive Medicine, Department of Obstetrics and Gynaecology, All India Institute of Medical \\ Sciences, New Delhi
}

\section{Dear Editor}

We read the recently published paper in your journal with great interest (Mattos et al., 2021). HSG-MRI can be a promising method for infertility evaluation. Although the study provides new insights into the HSG-MRI technique, as the reader, we would like to express some concerns based on the study analysis:

1. TVS is the preferred investigation method for a baseline assessment of ovarian and uterine pathology during the infertility workup (Vickramarajah et al., 2017; Practice Committee of the American Society for Reproductive Medicine, 2015). Ludwin et al. (2013) reported that 3D USG has 100\% diagnostic accuracy to diagnose uterine anomalies when compared with the gold standard of laparoscopy and hysteroscopy. Similarly, 3D-USG is comparable to MRI to detect uterine anomalies and to visualize extrauterine structures (Pleş et al., 2018).

2. HYCOSY/Sonosalpingography can assess tubal patency as well as XR-HSG, thus eliminating the need for XR-HSG/MRI-HSG (Luciano et al., 2014).

3. The article does not mention the indications for MRI

for the infertile couples recruited. This should be discussed, because of the limited indication of MRI in infertile couples. As mentioned above, most pelvic pathologies are detectable in USG, which is easily available in all clinical settings.

4. There was no disagreement concerning tubal patency, thus suggesting that MRI-HSG is not worse than XRHSG. Therefore, MRI-HSG can only be done for infertile couples undergoing MRI for some other indication.

5. Fertiliscan combines HyFoSy with a high-quality 3D-USG for detailed infertility evaluation (Levaillant et al., 2019). Fertiliscan evaluates the uterine cavity, the adnexa, the ovarian reserve and fallopian tube patency. This has more advantages when compared to MRI-HSG, since it is more cost effective, it can be performed in the office setting; USG is more commonly available and accessible as compared to MRI in low resource settings, and in developing countries. Fertiliscan helps assess antral follicle count but not the MRI. So, this is a one stop investigation for infertility workup.

6. Thus, we need further studies to compare Fertiliscan with MRI-HSG, to see their advantages, disadvantages and clinical application.

\section{CONFLICT OF INTEREST}

None

\author{
Corresponding Author: \\ Ankita Sethi \\ DM Reproductive Medicine Resident \\ Division of Reproductive Medicine \\ Department of Obstetrics and Gynecology \\ All India Institute of Medical Sciences \\ New Delhi, India \\ E-mail: drankita32@gmail.com
}

\section{REFERENCES}

Levaillant JM, Pasquier M, Massin N. A novel concept for female infertility exploration: the Fer-tiliscan (C), a dedicated all-in-one 3D ultrasound exploration. J Gynecol Obstet Hum Reprod. 2019;48:363-7. PMID: 30690086 DOI: 10.1016/j.jogoh.2019.01.008

Luciano DE, Exacoustos C, Luciano AA. Contrast ultrasonography for tubal patency. J Minim Invasive Gynecol. 2014;21:9948. PMID: 24910933 DOI: 10.1016/j.jmig.2014.05.017

Ludwin A, Pityński K, Ludwin I, Banas T, Knafel A. Two- and three-dimensional ultrasonography and sonohysterography versus hysteroscopy with laparoscopy in the differential diagnosis of septate, bicornuate, and arcuate uteri. J Minim Invasive Gynecol. 2013;20:90-9. PMID: 23312248 DOI: $10.1016 /$ j.jmig.2012.09.011

Mattos LA, Sauer LJ, Blasbalg R, Petta CA, Pereira RM, Carvalho LFP. Hysterosalpingography using Magnetic Resonance Imaging for infertility patients. JBRA Assist Reprod. 2021;25:40311. PMID: 33900058 DOI: $10.5935 / 1518-0557.20210002$

Pleş L, Alexandrescu C, Ionescu CA, Arvătescu CA, Vladareanu S, Moga MA. Three-dimensional scan of the uterine cavity of infertile women before assisted reproductive technology use. Me-dicine (Baltimore). 2018;97:e12764. PMID: 30313087 DOI: 10.1097/MD.0000000000012764

Practice Committee of the American Society for Reproductive Medicine. Diagnostic evaluation of the infertile female: a committee opinion. Fertil Steril. 2015;103:e44-50. PMID: 25936238 DOI: 10.1016/j. fertnstert.2015.03.019

Vickramarajah S, Stewart V, van Ree K, Hemingway AP, Crofton ME, Bharwani N. Subfertility: What the Radiologist Needs to Know. Radiographics. 2017;37:1587-602. PMID: 28898181 DOI: $10.1148 / \mathrm{rg} .2017170053$ 